\title{
Transformations of supported gold nanoparticles observed by in situ electron microscopy
}

Liu, Pei; Wu, Tiantian; Madsen, Jacob; Schiøtz, Jakob; Wagner, Jakob Birkedal; Hansen, Thomas Willum

Publication date:

2020

Document Version

Publisher's PDF, also known as Version of record

Link back to DTU Orbit

Citation (APA):

Liu, P., Wu, T., Madsen, J., Schiøtz, J., Wagner, J. B., \& Hansen, T. W. (2020). Transformations of supported gold nanoparticles observed by in situ electron microscopy. Abstract from Microscopy and Microanalysis 2020, Milwaukee, Wisconsin, United States.

\section{General rights}

Copyright and moral rights for the publications made accessible in the public portal are retained by the authors and/or other copyright owners and it is a condition of accessing publications that users recognise and abide by the legal requirements associated with these rights.

- Users may download and print one copy of any publication from the public portal for the purpose of private study or research.

- You may not further distribute the material or use it for any profit-making activity or commercial gain

- You may freely distribute the URL identifying the publication in the public portal 


\section{Transformations of supported gold nanoparticles observed by in situ electron microscopy}

Pei Liu ${ }^{1,2}$, Tiantian $\mathrm{Wu}^{3}$, Jacob Madsen ${ }^{4,5}$ Jakob Schiøtz ${ }^{4}$ Jakob Birkedal Wagner ${ }^{1}$ and Thomas Willum Hansen $^{1}$

${ }^{1}$ DTU Nanolab, Technical University of Denmark, DK-2800 Kongens Lyngby,Denmark

${ }^{2}$ Electron Microscopy for Materials Science, University of Antwerp, Groenenborgerlaan 171, 2020 Antwerp, Belgium

${ }^{3}$ Department of Energy Conversion and Storage, Technical University of Denmark, DK-2800 Kongens Lyngby, Denmark

${ }^{4}$ Department of Physics, Technical University of Denmark, DK-2800 Kongens Lyngby, Denmark ${ }^{5}$ Physics of Nanostructured Material, University of Vienna, Boltzmanngasse 5, 1090 Wien, Austria

Oxide supported metal nanoparticles play an important role in heterogeneous catalysis. However, understanding the metal/oxide interface and their morphology and structure and how these change under a gaseous environment remains challenging. Herein, we investigate the interface between $\mathrm{Au}$

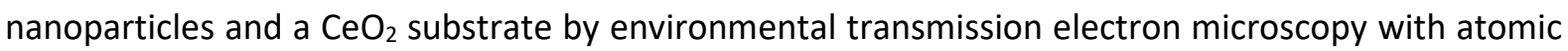
resolution. We find that the Au nanoparticles have two preferential epitaxial relationships with the substrate, i.e. Type I (111)[-110] $\mathrm{CeO}_{2} / /(111)[-110] \mathrm{Au}$ and Type II (111)[-110]CeO $/ /(111)[1-10] \mathrm{Au}$, where Type I is preferred. In situ observations in the presence of $\mathrm{O}_{2}$ show that the gas can stimulate the supported $\mathrm{Au}$ nanoparticles to transform between these two orientations even at room temperature [1]. Moreover, when increasing the temperature to $973 \mathrm{~K}$, the transformation of an $\mathrm{Au}$ nanoparticle between the two orientation states and a non-crystalline state in the presence of $\mathrm{O}_{2}$ is also observed. DFT calculations of the binding energy? between $\mathrm{Au}$ and $\mathrm{CeO}_{2}$ in the two relationships is strongly influenced by the presence of oxygen vacancies. For a given position of a vacancy, there is a significant energy difference between the energy of the two types. However, for some positions, Type I is preferred, and for others, Type II, but the most favorable position of the vacancy for the two types has a very similar energy. This is consistent with the observation of both types of adhesion.

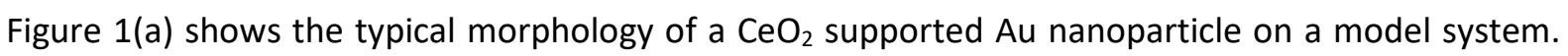
The shape of the commercial $\mathrm{CeO}_{2}$ support nanoparticles is normally octahedral with eight (111) surfaces. Two distinct crystalline orientation relationships between $\mathrm{Au}$ and the ceria support were observed. The distribution of these two types of relationships was measured on the model sample and was found to be $62 \%$ Type I and $38 \%$ Type II on 131 Au nanoparticles (Fig. 1(b)). The $25 \%$ lattice misfit that gives rise to a network of interfacial dislocations is formed to accommodate the strain that exists at the interface.

To obtain detailed information of the structural transformation process, image sequences of supported gold nanoparticles showing the transformations were acquired in situ during exposure to $4.5 \mathrm{~Pa} \mathrm{O}_{2}$ at $973 \mathrm{~K}$. Under these conditions, the nanoparticles change continuously between three structural states. Figures $2 \mathrm{~A}, \mathrm{~B}, \mathrm{C}$ show the structural transformation, which mainly occurs between the non-crystalline state, Type I and Type II. A timeline indicating the state of the particle is shown in Fig. 2D. The lifetime for Type II is shorter than that of Type I, which indicates a difference in energy of the two states. 
This melting/resolidification phenomenon is suggested to be a result of the nanoscale size of the particles [2], the adsorption of oxygen on the surface [3] and the interaction with the $\mathrm{CeO}_{2}$ support [4]. All of these factors can give rise to a depression of the melting point of the Au nanoparticles.

Here, further measurements of the dynamics of the $\mathrm{Au} / \mathrm{CeO}_{2}$ system along with analysis approaches will be discussed.

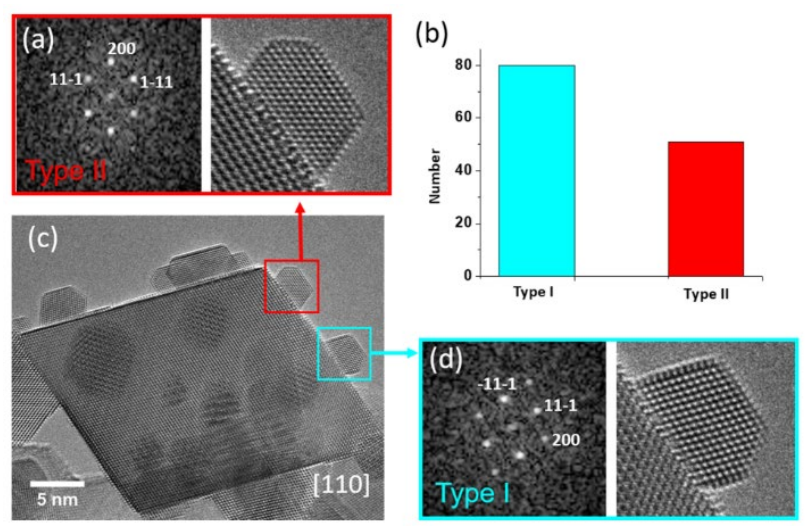

Figure 1: Typical morphology of the as-received $\mathrm{Au} / \mathrm{CeO}_{2}$ sample along with the occurrence of the two states.
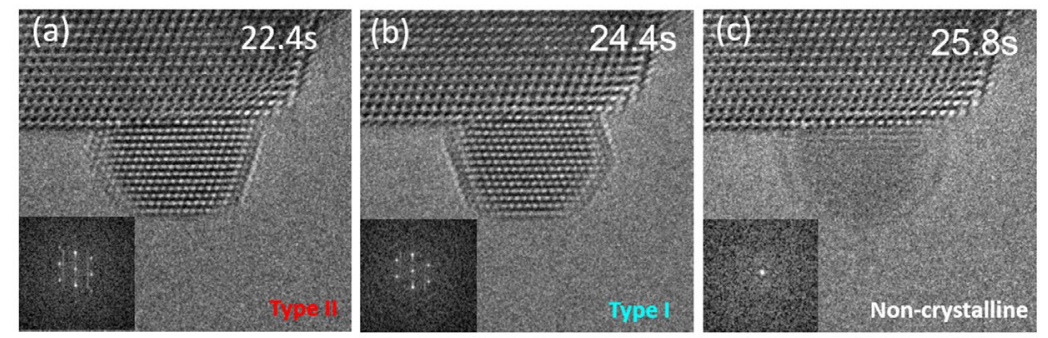

(d)

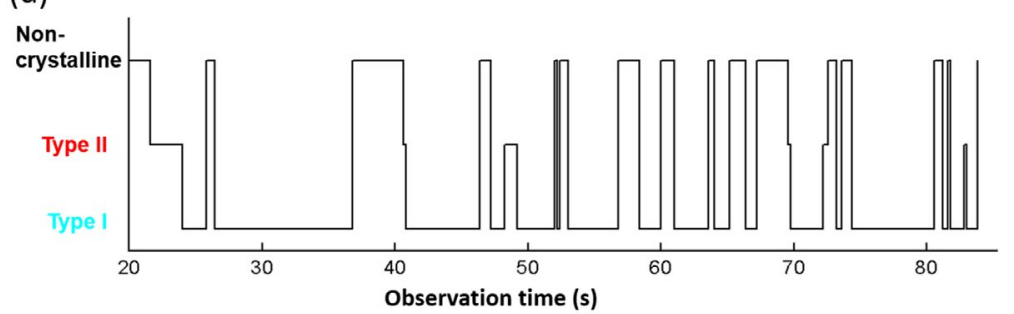

Figure 2: Different configurations of the ceria supported Au nanoparticles along with a timeline of the states.

[1] P. Liu, T. T. Wu, J. Madsen et al., Nanoscale 11, (2019) 11885-11891.

[2] P. Schlexer, A. B. Andersen, B. Sebok et al., Part. Part. Syst. Charact. 36, (2019) 7.

[3] N. D. S. Canning, D. Outka, R. J. Madix, Surf. Sci. 141, (1984) 240-254.

[4] J. Lee, T. Tanaka, J. Lee et al., Calphad-Comput. Coupling Ph. Diagrams Thermochem. 31, (2007) 105-111. 